\title{
Do International Commission of Agricultural and Biosystems Engineering (CIGR) dimension recommendations for loose housing of cows improve animal welfare?
}

\author{
Alice de Boyer des Roches, ${ }^{1 *}$ Romain Lardy, ${ }^{1}$ Jacques Capdeville ${ }^{2}$ Luc Mounier, ${ }^{1}$ and Isabelle Veissier ${ }^{1}$ \\ ${ }^{1}$ Université Clermont Auvergne, INRA, VetAgro Sup, UMR Herbivores, 63122 Saint-Genès-Champanelle, France \\ ${ }^{2}$ Institut de l'Elevage, Antenne de Toulouse-Castanet Tolosan, 31321 Castanet Tolosan Cedex, France
}

\section{ABSTRACT}

Design of cubicles and self-locking barriers can affect cow skin alterations, lameness, and dirtiness. We investigated whether the International Commission of Agricultural and Biosystems Engineering (CIGR, Gainesville, FL)-recommended cattle housing design and dimensions actually improve cow welfare. We recorded individual cow body dimensions and assessed skin alterations, dirtiness, and lameness on 3,841 cows from 131 loose housing dairy farms (76 farms with cubicles and 55 straw-yard systems). We recorded the dimensions of cubicles (e.g., width, length, and so on) and of the self-locking barrier (e.g., top rail height and so on) for each farm. We then compared whether these dimensions would match with the individual cow body dimensions and whether compliance was associated with the occurrence of skin alterations, lameness, and dirtiness. Most cows (69.2\%) had at least one skin alteration, on the tarsus (41.2\%); neck, shoulder, or back $(28.2 \%)$; hindquarters $(22.0 \%)$; carpus $(21.2 \%)$; and flank, side, or udder (11.6\%). Lameness prevalence reached $17.9 \%$. Most cows $(83.1 \%)$ were scored dirty in at least one body region, mainly on the lower hind legs including hocks (81.4\%), hindquarters $(41.8 \%)$, and udder (21.0\%). Cubicle recommendations were mostly met for cubicle resting length (75.9\% of cubicles) and neck rail distance (NRD, 60.7\%) but less so for overall cubicle length (CL, 38.8\%), cubicle width (CW, 30.9\%), neck rail height (NRH, 22.5\%), head space (HS, 15.8\%), partition zone for controlling lying position (ii zone, $15.7 \%$ ), head and lunging space (HLS, 10.6\%), partition head zone (i zone, 9.4\%), and partition zone for pelvis freedom (iii zone, $6.0 \%$ ). Compliance with design recommendations was associated with fewer skin altera-

Received December 12, 2018.

Accepted June 29, 2019.

*Corresponding author: alice.deboyerdesroches@vetagro-sup.fr tions on neck (recommendation met for CW, CL, HS, and NRD and i zone), hindquarters (CW, CL, NRD), tarsus (CW, i and ii zones), and carpus (CW, HS, i and ii zones); less lameness (CW, NRH, i zone); and less dirtiness on the hindquarters (CW, HLS, NRD), lower hind legs (iii zone), and udder (CW, CL, HLS, NRD). Compliance with recommended i zone and ii zone design was associated with less injury and lameness but more dirtiness, whereas the opposite was true for the iii zone. Self-locking barrier recommendations were mostly met for bottom rail height $(68.2 \%)$, separation wall width (SWW, 68.3\%), and top rail height (TRH, $56.9 \%$ ) and less often met for separation wall height $(36.3 \%)$ and height difference between feeding floor and walking alley (26.5\%). Risk for skin alterations on carpus and neck only decreased when SWW and TRH met recommendations. In conclusion, compliance with CIGR recommendations for some cubicle dimensions and neck rail position was associated with lower risk for cow welfare. However, the CIGR recommendations on cubicle partitions and self-locking barriers still leave welfare at risk and so need to be refined through further research with close observation of cow lying and feeding behavior.

Key words: dairy cow, loose housing, cow welfare, equipment dimensions

\section{INTRODUCTION}

Skin alterations, lameness, and dirtiness of dairy cows are associated with pain (Prunier et al., 2013) or diseases such as environmental mastitis (Schreiner and Ruegg, 2003; Reneau et al., 2005) and are, thus, likely to result in poor welfare. Their prevalence varies greatly between countries and studies. Skin injury on the hocks affects between 27\% (Veissier et al., 2004) and $57 \%$ of cows (Kielland et al., 2009). Dirtiness is generally more frequent on the legs (e.g., $100 \%$ of cows in Whay et al., 2003, vs. $33 \%$ in Zurbrigg et al., 2005) than on the flank (e.g., $11 \%$ of cows in Whay et al., 
2003 ) or udder (13\% of cows in Whay et al., 2003, vs. $14.6 \%$ in Zurbrigg et al., 2005). Lameness is reported in 20 to $32 \%$ of cows (e.g., $21.5 \%$ in Cook, 2003; $31 \%$ in Dippel et al., 2009). It is essential to identify the risk factors of such problems to improve cow welfare (European Food Safety Authority, 2012).

The dimensions of the cubicles and feeding barriers are known to affect skin alterations, lameness, and cleanliness of dairy cows kept in loose housing systems (European Food Safety Authority, 2009). Skin alterations occur at areas of the body that are in repeated contact with elements of the housing facilities (Weary and Taszkun, 2000). For instance, neck lesions are associated with a narrow (e.g., less than $63 \mathrm{~cm}$ ) manger (Kielland et al., 2010), and hock lesions are associated with cubicles having a high curb or high neck rail (Veissier et al., 2004). Lameness has a multifactorial and complex etiology, but equipment dimensions are clearly a major risk factor: lameness is more prevalent when cubicles are too narrow (Sogstad et al., 2005) or too short (Dippel et al., 2009). Cubicles are designed to encourage the cow to lie in the cubicle but defecate and urinate in the alley (Fregonesi et al., 2009). Hence, cow dirtiness is associated with cubicle features (Veissier et al., 2004; Ruud et al., 2010a) or space allowance (Fregonesi and Leaver, 2002). For instance, the further the neck rail, the higher the prevalence of dirty udders (Fregonesi et al., 2009).

The International Commission of Agricultural Engineering (CIGR, Gainesville, FL) produced recommendations for the housing of dairy cows and heifers in 1994 (CIGR, 1994) and issued an updated version in 2014 (CIGR, 2014). The CIGR proposes dimensions for cubicles or tiestalls and feeding barriers based on cow body dimensions. Experts formulated these recommendations based on their knowledge of the natural positions and movements of cows when standing up, lying down, or eating. Indeed, taking into account body dimensions for equipment design improves the prediction of risks to welfare (Kielland et al., 2009; de Boyer des Roches et al., 2013). A study in Canadian dairy farms showed that the majority of farms do not follow the Dairy Farmers of Canada and National Farm Animal Care Council (2009) code of practice for tiestall dimensions, and this lack of compliance increased the risk for skin injury and lameness but tended to reduce cleanliness (Bouffard et al., 2017). To our knowledge, the pro-welfare effect of following recommendations has never been checked on animals housed in cubicles.

The objectives of this study are to describe the extent to which dairy farms met the CIGR recommendations for cubicles and self-locking barrier dimensions and to check whether meeting these recommendations was associated with less skin alterations, lameness, and dirtiness.

\section{MATERIALS AND METHODS}

\section{Farms Surveyed}

We visited 131 commercial dairy farms in 2 French regions (lowlands in western France-Brittany and Pays de Loire - and highlands in central and eastern France-Auvergne and Rhône-Alpes). All the farms were family run, and the cows were housed in loose housing systems. In total, 75 farms (2,366 cows) had cubicles and self-locking barriers, and 55 farms (1,435 cows) had straw-yard and self-locking barriers. One farm (38 cows) had cubicles and individual mangers and was therefore excluded from the feeding system model (see the following). Cows were milked in a parlor or by an automatic milking system. Herd size ranged from 21 to 120 dairy cows of Montbéliarde (French dual-purpose breed) or Holstein breeds. Details on sampling of farms can be found in de Boyer des Roches et al. (2014, 2016). Each farm was visited once. The organization of the farm visit followed the Welfare Quality protocol (Welfare Quality, 2009). On each farm, a sample of cows was chosen at random. Size of the sample depended on size of the herd. If a herd had 30 or fewer lactating cows, all the animals were observed, otherwise, 75 to $45 \%$ of cows were randomly chosen, with the proportion decreasing with increasing herd size (e.g., 30 cows out of 30,44 cows out of 80,54 cows out of 120). Details of sampling size according to herd size for cow observation can be found in the Welfare Quality (2009) protocol. The visits were carried out by 5 observers who had been pretrained by a Welfare Quality project partner in recording skin alterations, dirtiness, and lameness and by the principal investigator in recording cow-body and farm-equipment dimensions. During training on 4 farms, the observers' results were compared against each other's and against reference values to ensure accuracy and reproducibility between observers (de Boyer des Roches et al., 2014). Observer agreement with reference values ranged from 74 to $96 \%$ (C. Winckler, University of Natural Resources and Life Sciences, Vienna, Austria, personal communication)

\section{Measurements on Cows}

Skin alterations, dirtiness, and lameness were recorded by direct observation according to the Welfare Quality protocol (Welfare Quality, 2009), as described in brief below. When the cows were blocked at the selflocking barrier, the observer stood less than $2 \mathrm{~m}$ from 
a focus cow, on one side of the body chosen at random, and recorded the number of hairless patches, lesions, and swellings on 5 body regions (Figure 1). A hairless patch was defined as "an area with hair loss, where the skin is not damaged or as an extensive thinning of the coat due to parasites." A lesion corresponded to "damaged skin either in the form of a scab or a wound, or dermatitis due to ecto-parasites, or completely or partly missing teats, or ear lesion due to torn off ear tags." A swelling corresponded to "an obvious increase in circumference compared with sound state." We pooled all types of skin alterations for further analyses. The observer assessed dirtiness on the same side of the cow, on lower hind legs, hindquarters, and udder (Figure 1). Lower hind legs and hindquarters were considered dirty if there were plaques of dirt amounting to the size of the palm of a hand or if more than half the focal area was covered. The udder was considered dirty if there were distinct plaques of dirt on udder or any dirt on and around the teats. Height at withers and diagonal body length of the cow were then taken using a measuring rod (Figure 1, Table 1; CIGR, 2014). The cows were, on average, $143.4 \mathrm{~cm}$ high (minimum, 125.0; maximum, 176.0) and $159.3 \mathrm{~cm}$ long (minimum, 131.0; maximum, 189.0). Then the cow was released from the self-locking barrier. Its gait was observed from the side or from behind when it was walking in a straight line on a hard, level, nonslippery surface. The cow was considered lame as soon as we observed any imperfect temporal rhythm in stride creating a limp.

\section{Dimensions of Cubicles and Self-Locking Barriers}

The type and dimensions of the cubicles or self-locking barriers sometimes varied within farm (e.g., some farms had more than one type of cubicle or more than one type of self-locking barrier). We therefore recorded the number of cubicles of each type and the number of selflocking barriers of each type. Then, we chose at random one cubicle per type and one self-locking barrier per type to precisely measure them, using a telemeter (Aga Tep laser distance meter, AGATEC, Stratford Upon Avon, UK). On each cubicle of a given type, we measured the width (i.e., distance between cubicles partitions), brisket board position (distance from the curb, height, and width), neck rail position (distance from the curb, height), and first obstacle position (distance from the curb; Table 1, Figure 2A). We also recorded the position of each cubicle partition element (Table 1, Figure 2B). The reference for measures was curb in the horizontal plane and lying floor on the vertical plane.

On each self-locking barrier of a given type, we measured the top rail height, bottom rail height, height and width of the separation wall, and the difference

\section{Body dimensions}

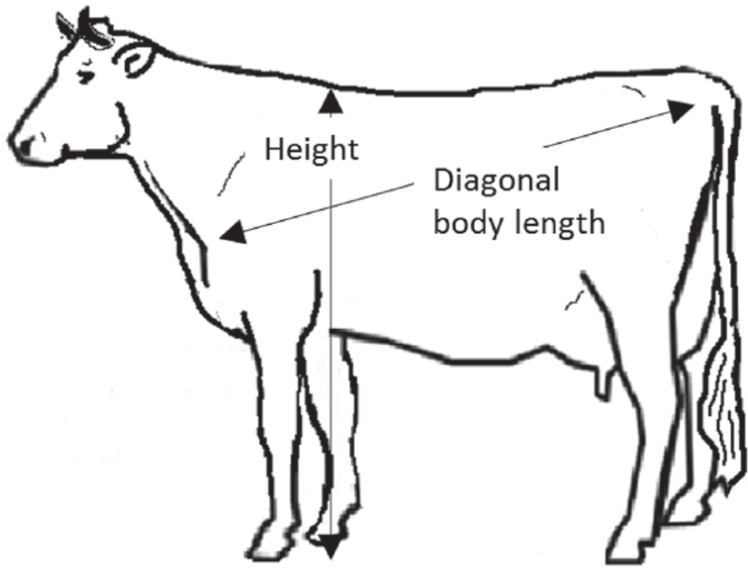

\section{Body regions observed for} skin alterations
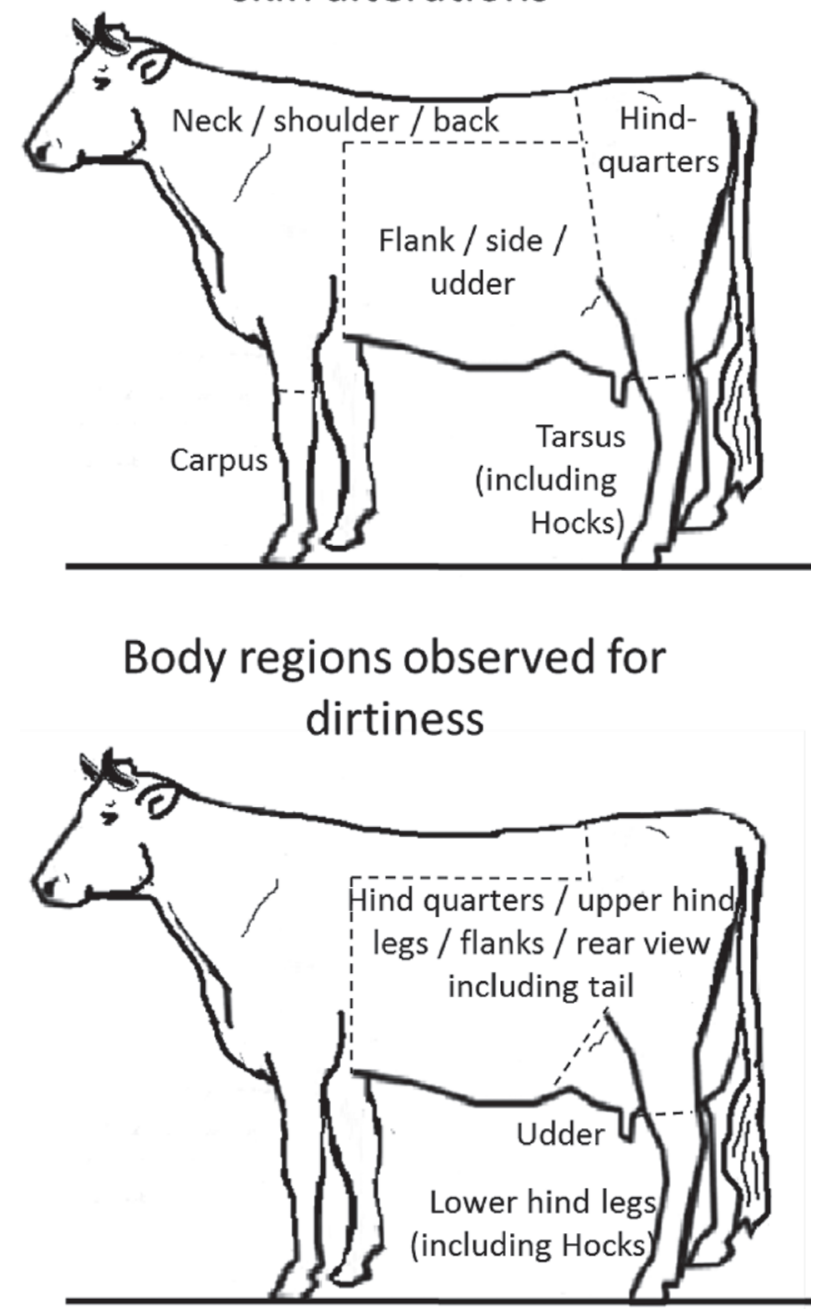

Figure 1. Cow body-dimension measurements (height, width, diagonal length) and body areas observed for skin alterations and for dirtiness (Welfare Quality, 2009). 
in height between the alley floor and the feeding floor (Figure 2C, Table 1). Walking floor was the reference.

\section{CIGR-Recommendation Indicators}

The CIGR provides recommendations for cubicles and self-locking barrier (Table 2, Figure 3) according to cow height and length. Based on the dimensions recorded (Table 1, Figure 2), we modeled each cubicle and each self-locking barrier (Supplemental Figure S1; https://doi.org/10.3168/jds.2018-16154). This information was used to check the accuracy of the on-farm data recorded and determine the presence or absence of any obstacle within the cubicle zones for head (zone i), controlling lying position (zone ii), and pelvis freedom preventing injury to hips and ribs (zone iii; Figure $3 \mathrm{C})$. Then, we compared the recommended dimensions (Table 2) to those observed on farm. For instance, we considered that cubicle width met the recommendation if it was equal to or wider than $0.83 \times$ cow height; for $\mathrm{i}$, ii, and iii zones, we considered that the recommendation was met if no obstacle was in the zone.

\section{Statistical Analyses}

The analysis included a total of 3,839 cows. In total, we surveyed 76 farms with cubicles: 30 farms had 1 type of cubicles, 30 farms had 2 types of cubicles, 10 farms had 3 types of cubicles, and 6 farms had 4 types of cubicles. Regarding self-locking barriers, we surveyed 127 farms in total: 85 farms with 1 type of self-locking barrier, 37 farms with 2 types of self-locking barriers, and 5 farms with 3 types of self-locking barriers. Among the 3.839 cows, 2,404 were housed in cubicle systems, so they were kept to analyze the effects of cubicle design (data set 1); 3,801 cows were housed in cubicle or straw-yard systems with access to a self-locking feeding barrier, so they were kept for self-locking barrier modeling (data set 2); and 2,366 cows were housed in cubicle with access to a self-locking feeding barrier (data set 3 ). Then, we linked each cow to each cubicle and to each feeding rack on its farm. Finally, we obtained 4,649 cow-cubicle pairs, 5,137 cow-self-locking barrier pairs, and 5,908 cow-cubicle-self-locking barrier triplets.

First, we built Boolean data. For each cow, we took into account the presence versus absence of skin alterations on each body part, whether each body part was dirty versus clean, and whether the cow was lame or not. For each equipment, we took into account whether a given element (neck rail, brisket board, and so on) followed the CIGR recommendation or not.

Second, we used univariable logistic regression to assess the likelihood that a cow was injured, lame, or dirty on a given body part according to each equipment

Table 1. Measures performed on cow body dimensions, cubicles, and self-locking barriers on the 131 dairy farms

\begin{tabular}{ll}
\hline Category and measure & Type of data \\
\hline Animal & \\
Body dimensions (Figure 1) & \\
Cow height (at withers) & Numeric $(\mathrm{cm})$ \\
Cow diagonal body length & Numeric $(\mathrm{cm})$ \\
Cubicle & Category \\
Type of cubicle: head-to-head space sharing vs. other & Numeric $(\mathrm{cm})$ \\
Cubicle width: distance between the cubicle partitions & Numeric $(\mathrm{cm})$ \\
Neck rail & Numeric $(\mathrm{cm})$ \\
Height: vertical neck rail distance from the floor & \\
Distance: horizontal neck rail distance from the curb & Numeric $(\mathrm{cm})$ \\
Brisket board & Numeric $(\mathrm{cm})$ \\
Height: vertical brisket board distance from the floor & \\
Distance: horizontal brisket board distance from the curb & Numeric $(\mathrm{cm})$ \\
Elements of the cubicle partition (Figure 3) & Numeric $(\mathrm{cm})$ \\
Height: vertical element distance from the floor & Category \\
Distance: horizontal element distance from the curb & Numeric $(\mathrm{cm})$ \\
Obstacle in front of the cow & Numeric $(\mathrm{cm})$ \\
Type: wall vs. rail vs. straw bale vs. other vs. none & Numeric $(\mathrm{cm})$ \\
Height: vertical obstacle top distance from the floor & \\
Space under: vertical obstacle bottom distance from the floor & Numeric $(\mathrm{cm})$ \\
Distance: horizontal obstacle distance from the curb & Numeric $(\mathrm{cm})$ \\
Self-locking barrier & Numeric $(\mathrm{cm})$ \\
Top rail height: distance between the top rail and the floor & Numeric $(\mathrm{cm})$ \\
Bottom rail height: distance between the bottom rail and the floor & Numeric $(\mathrm{cm})$ \\
Separation wall width & \\
Separation wall height & \\
Height difference between feeding floor and walking alley & \\
\hline
\end{tabular}



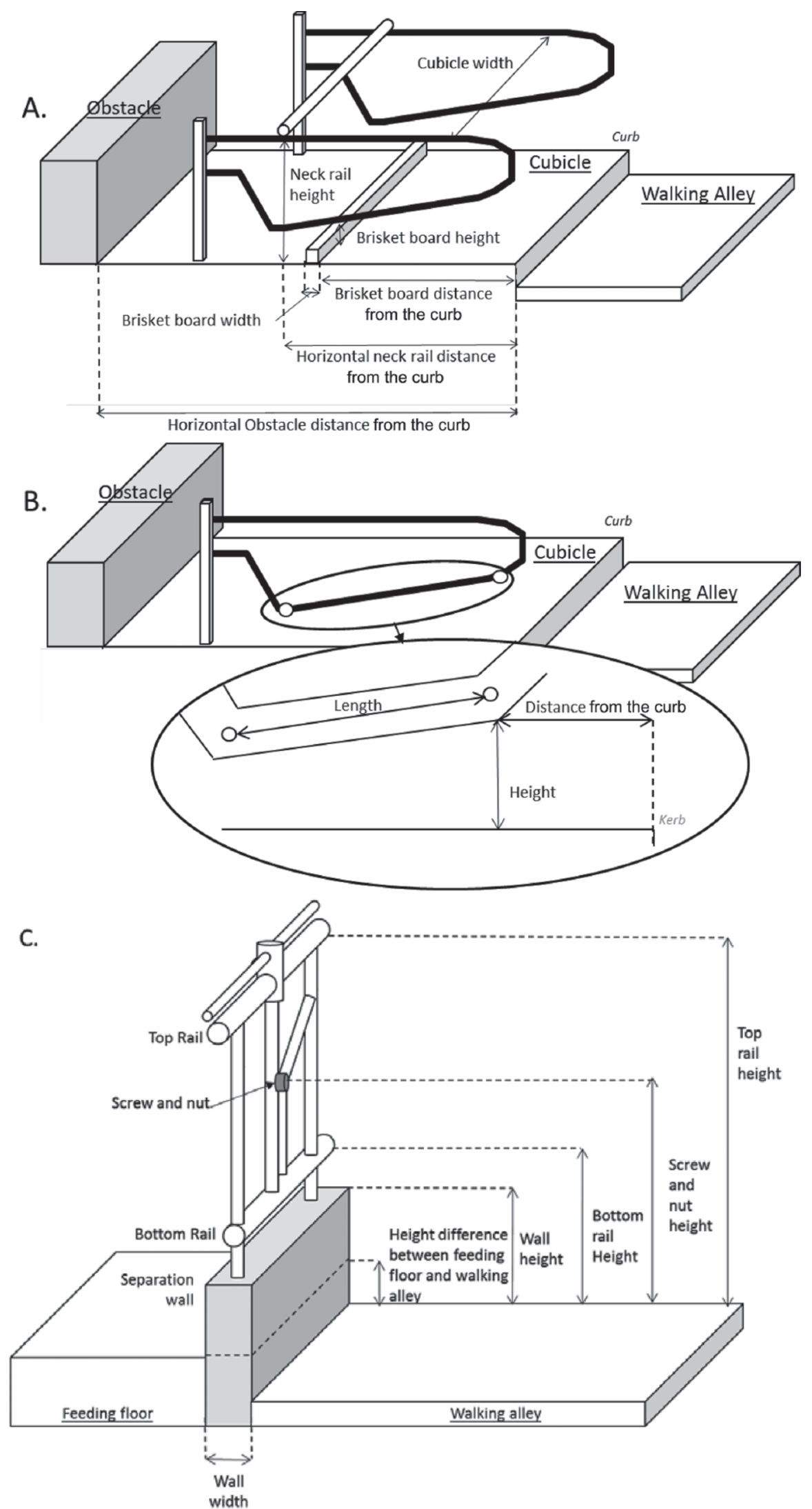

Figure 2. Measures performed on the cubicles (A, B) and on the self-locking barriers (C). 
Table 2. International Commission of Agricultural and Biosystems Engineering (CIGR, 2014) recommendations on dimensions for cubicles and self-locking barriers and requirement for each recommendation to be met

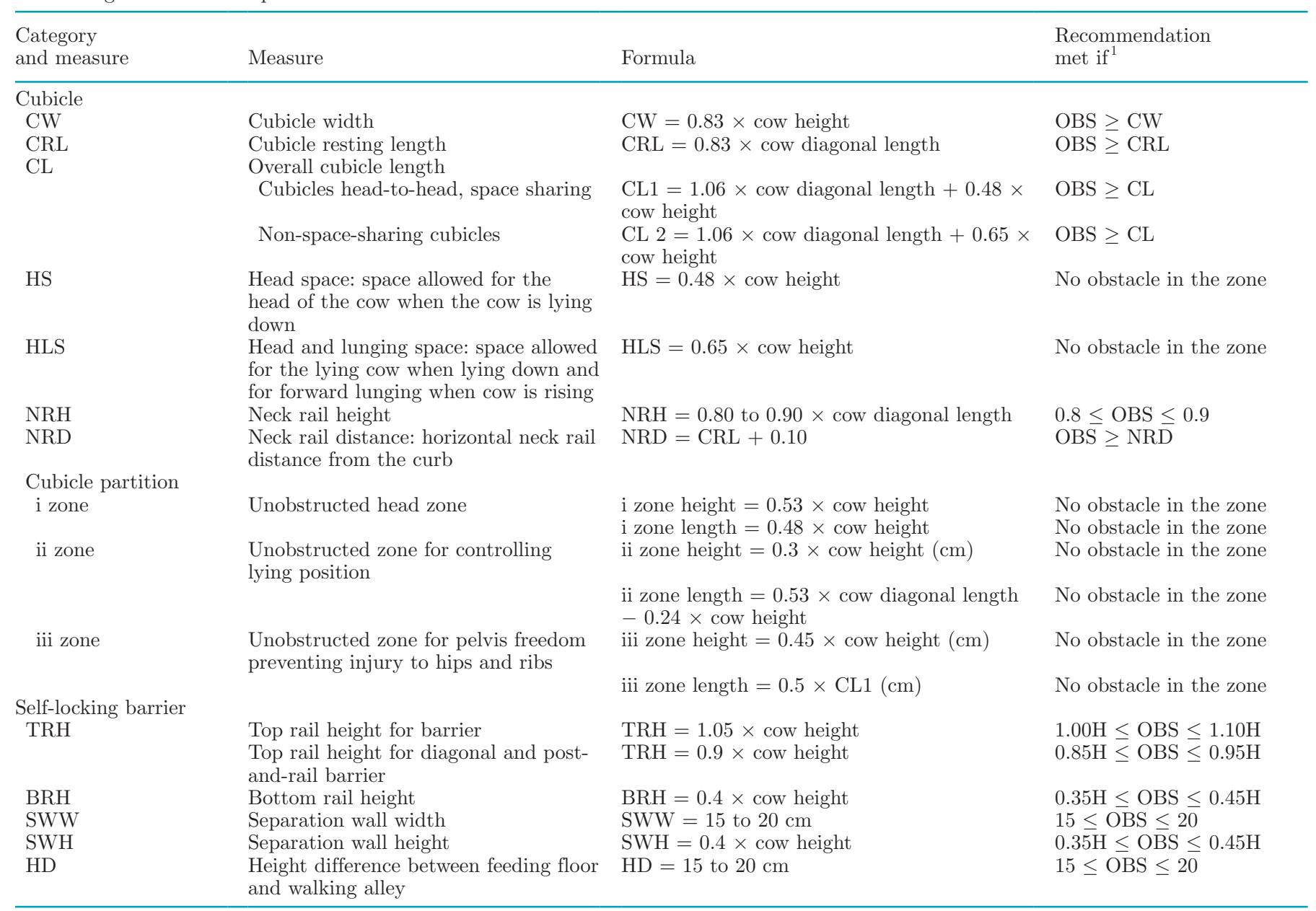

${ }^{1} \mathrm{OBS}=$ observation; $\mathrm{H}=$ height.

element. The type and dimensions of the cubicles or self-locking barriers sometimes varied within farm (e.g., some farms had 4 types of cubicles), so in these cases, we assumed that the effect of a given type of cubicle or self-locking barrier was proportional to its proportion on the farm (e.g., a type of cubicle representing $80 \%$ of the cubicles on a farm is assumed to potentially explain $80 \%$ of injuries). We thus used weighted least square regression, where the weight factor was the proportion of the cubicles (or barriers) on the farm. The factors with a probability of effect of 0.05 or less were kept to build a multivariable full model.

Third, the full model was then simplified by backward elimination according to the Akaike's information criterion (Akaike, 1973). The simplification was stopped when no factor that would decrease the Akaike's information criterion value could be removed (Burnham et al., 2011). Finally, among models with close Akaike's information criterion values $(\Delta<2)$, we selected the most parsimonious (i.e., the model with the fewest parameters with a $P$-value below 0.05 ).

All calculations were done using R 3.4.4 software (R Core Team, 2018).

\section{RESULTS}

\section{Skin Alteration, Dirtiness, and Lameness}

In data set 1 , almost $70 \%$ of the cows had skin alterations, $83.1 \%$ were dirty on at least one body part, and $17.9 \%$ were lame (Table 3 ). Skin alterations were mainly located at the tarsus ( $41.2 \%$ of cows) and neck, shoulder, or back ( $28.2 \%$ of cows) and less frequent on hindquarters $(22.0 \%$ of cows), carpus $(21.2 \%$ of cows $)$, and flank, side, or udder ( $11.6 \%$ of cows). Dirtiness was mainly detected on the lower hind legs, including hocks ( $81.4 \%$ of cows), and to a lesser extent on the hind quarters-upper hind legs, flank, and rear view including 


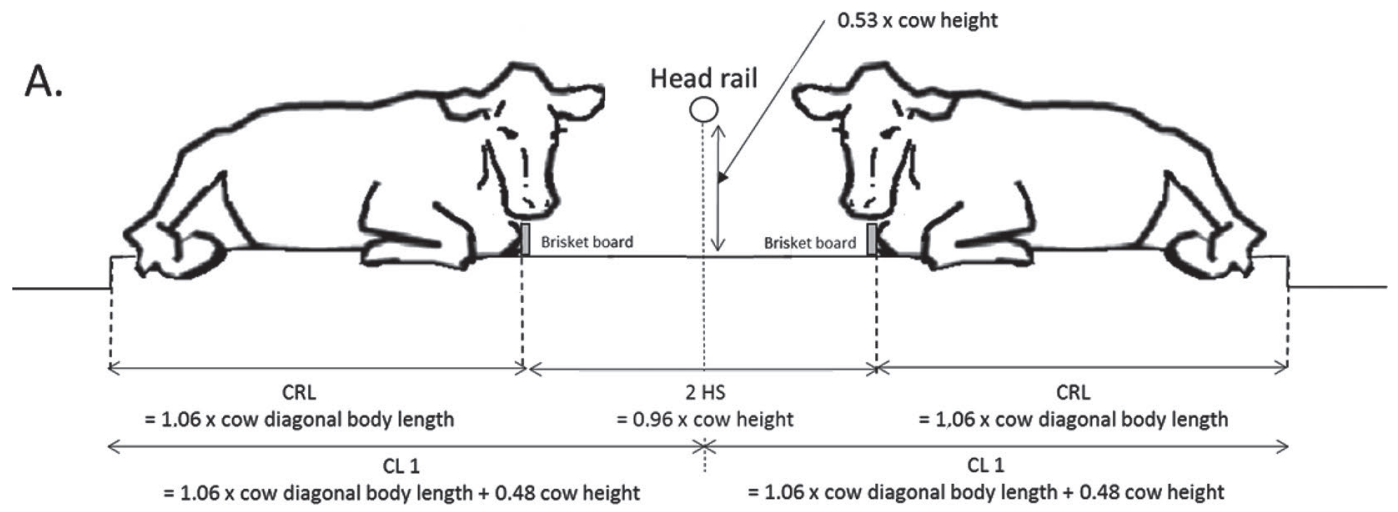

B.

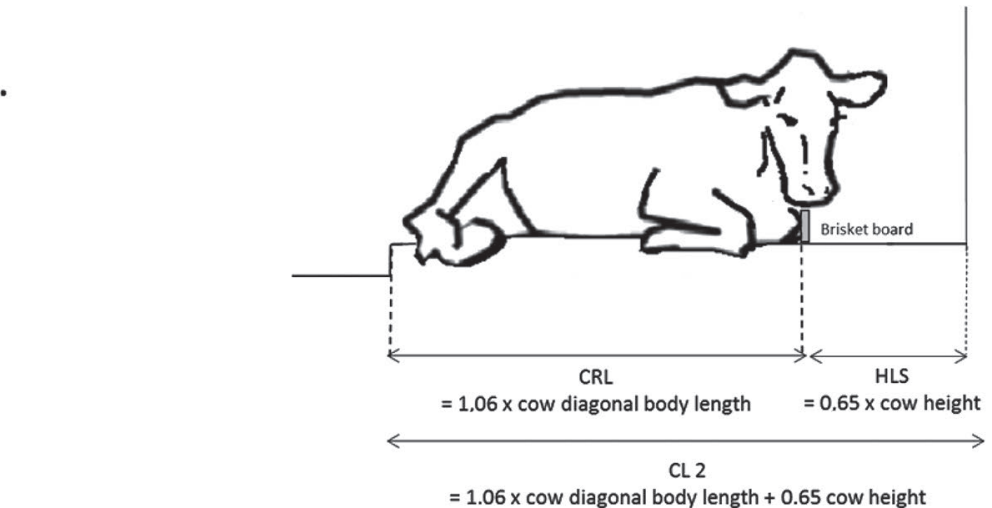

C.

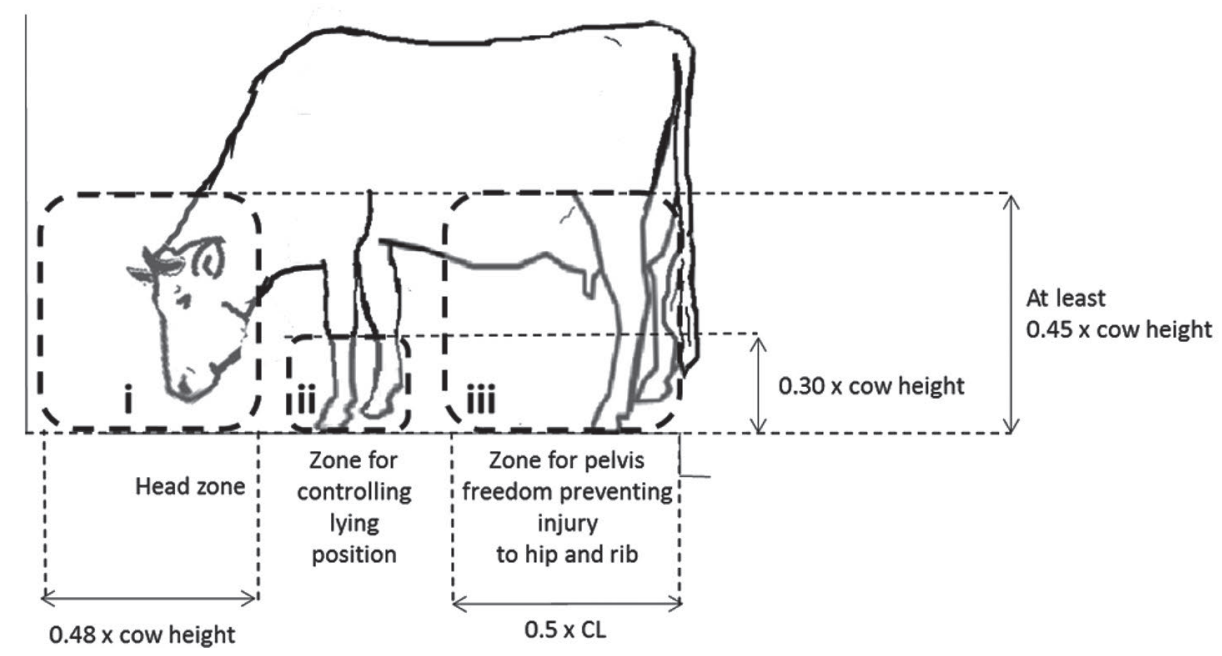

Figure 3. The International Commission of Agricultural and Biosystems Engineering (CIGR, Gainesville, FL) recommendation indicators for dimensions of cubicles with head-to-head space sharing (A) or not (B) and unobstructed cubicle partition areas (C): head zone (i), zone for controlling lying position (ii), and zone for pelvis freedom preventing injury to hip and rib (iii). CRL = cubicle resting length; HS = head space; $\mathrm{CL}=$ overall cubicle length; HLS $=$ head and lunging space.

tail (41.8\% of cows). Dirty udder was found on $21.0 \%$ of cows. In data set 2 , cows had skin alterations mainly on neck, shoulder, or back (29.0\% of cows) and to a lesser extent on carpus (14.0\%). In data set 3, cows had skin alterations mainly on neck, shoulder, or back $(28.4 \%$ of cows) and to a lesser extent on carpus (20.7\%).

\section{Equipment Meeting CIGR Recommendations}

The CIGR recommendations for cubicles (data set 1) were often met for cubicle resting length (CRL, $75.9 \%$ of all possible cow-cubicle pairings) and neck rail distance (NRD, 60.7\%). They were less often met for 
overall cubicle length (CL, 38.8\%), cubicle width (CW, $22.5 \%$ ), and neck rail height (NRH, 30.9\%). They were rarely met for head space (HS, $15.8 \%$ ), cubicle partition zone of freedom for controlling lying position (ii zone, $15.7 \%$ ), head and lunging space (HLS, 10.6\%), head zone (i zone, 9.4\%), and cubicle partition zone for pelvis freedom preventing injury to hips and ribs (iii zone, 6.0\%; Supplemental Tables S1 and S2; https:// doi.org/10.3168/jds.2018-16154).

The CIGR recommendations for self-locking barrier (data set 2) were often met for bottom rail height (BRH, 68.2\%), separation wall width (SWW, 68.3\%), and top rail height (TRH, 56.9\%). They were less often met for separation wall height (SWH, 36.3\%) and height difference between feeding floor and walking alley (HD, 26.5\%; Supplemental Tables S1 and S2; https: //doi.org/10.3168/jds.2018-16154).

\section{Association Between CIGR Recommendations for Cubicles and Skin Alterations, Dirtiness, and Lameness}

Depending on the welfare aspect considered (skin alterations, dirtiness, or lameness), meeting CIGR recommendations for cubicle dimensions (data set 1) did not affect cows similarly (Tables 4 and 5). Only significant results are presented below $(P<0.05)$.

According to the final models for skin injury, the risks for skin injury on any body part decreased when cubicles met recommendations for $\mathrm{CW}$ (odds ratio, $\mathrm{OR}=0.76), \mathrm{CL}(\mathrm{OR}=0.78)$, i zone $(\mathrm{OR}=0.53)$, and ii zone $(\mathrm{OR}=0.59)$. The risks for carpus injury de- creased when cubicles met recommendations for CW $(\mathrm{OR}=0.61)$, HS $(\mathrm{OR}=0.66)$, i zone $(\mathrm{OR}=0.42)$, and ii zone $(\mathrm{OR}=0.42)$ but increased when cubicles met recommendations for CL $(\mathrm{OR}=2.0)$ and iii zone $(\mathrm{OR}=2.55)$. The risks for neck, shoulder, or back injury decreased when cubicles met recommendations for $\mathrm{CW}(\mathrm{OR}=0.75), \mathrm{CL}(\mathrm{OR}=0.63), \mathrm{HS}(\mathrm{OR}=$ $0.49), \operatorname{NRD}(\mathrm{OR}=0.51)$, and i zone $(\mathrm{OR}=0.42)$ but increased when cubicles met recommendations for HLS $(\mathrm{OR}=3.68)$ and iii zone $(\mathrm{OR}=2.00)$. The risks for udder injury decreased when cubicles met recommendations for ii zone $(\mathrm{OR}=0.62)$ but increased when cubicles met recommendations for $\mathrm{CW}(\mathrm{OR}=2.10)$ and NRD $(\mathrm{OR}=1.56)$. The risks for hindquarters injury decreased when cubicles met recommendations for $\mathrm{CW}(\mathrm{OR}=0.69), \mathrm{CL}(\mathrm{OR}=0.63)$, and $\mathrm{NRD}$ $(\mathrm{OR}=0.58)$ but increased when cubicles met recommendations for HS $(\mathrm{OR}=1.64)$. The risks for a tarsus injury decreased when cubicles met recommendations for $\mathrm{CW}(\mathrm{OR}=0.68)$, i zone $(\mathrm{OR}=0.51)$, and ii zone $(\mathrm{OR}=0.60)$.

According to the final models for dirtiness, the risks for any dirty body part decreased when cubicles met recommendations for iii zone $(\mathrm{OR}=0.47)$ but increased when cubicles met recommendations for CW $(\mathrm{OR}=1.55)$ and $\mathrm{i}$ zone $(\mathrm{OR}=1.63)$. The risks for dirty lower hind legs including hocks decreased when cubicles met recommendations for iii zone $(\mathrm{OR}=0.51)$ but increased when cubicles met recommendations for $\mathrm{CW}(\mathrm{OR}=1.57)$ and i zone $(\mathrm{OR}=1.72)$. The risks for dirty hindquarters, upper hind legs, or flank and rear view including tail decreased when cubicles met recom-

Table 3. Prevalence (no. and percentage of cows) of skin alterations, lameness, and dirtiness in 2,404 cows observed for cubicles, 3,801 cows observed for self-locking barriers, and 2,366 observed for cubicles and self-locking barriers

\begin{tabular}{|c|c|c|c|c|c|c|c|c|c|}
\hline Item & \multicolumn{3}{|c|}{$\begin{array}{l}\text { Data set 1: } \\
\text { Cubicles }\end{array}$} & \multicolumn{3}{|c|}{$\begin{array}{c}\text { Data set 2: } \\
\text { Self-locking barriers }\end{array}$} & \multicolumn{3}{|c|}{$\begin{array}{c}\text { Data set } 3: \\
\text { Cubicles and } \\
\text { self-locking barriers }\end{array}$} \\
\hline No. of cows studied & 2,404 & & & 3,801 & & & 2,366 & & \\
\hline \multicolumn{10}{|l|}{ Skin alterations } \\
\hline Neck, shoulder, or back & 677 & 28.2 & 0.25 & 1,102 & 29.0 & 0.34 & 671 & 28.4 & 0.25 \\
\hline Flank, side, or udder & 279 & 11.6 & 0.37 & - & - & - & - & - & - \\
\hline Hindquarter & 530 & 22.0 & 1.25 & - & - & - & - & - & - \\
\hline Tarsus (including hocks) & 990 & 41.2 & 5.2 & - & - & - & - & - & - \\
\hline Lameness & 430 & 17.9 & 2.91 & - & - & - & - & - & - \\
\hline \multicolumn{10}{|l|}{ Dirtiness } \\
\hline Any body part & 1,999 & 83.1 & 0.17 & - & - & - & - & - & - \\
\hline
\end{tabular}


Table 4. Coefficient of multivariable logistic regression models between International Commission of Agricultural and Biosystems Engineering (CIGR) recommendations for cubicles, self-locking barriers, and cubicles + self-locking barriers and prevalence of skin alterations, lameness, and dirtiness in cows

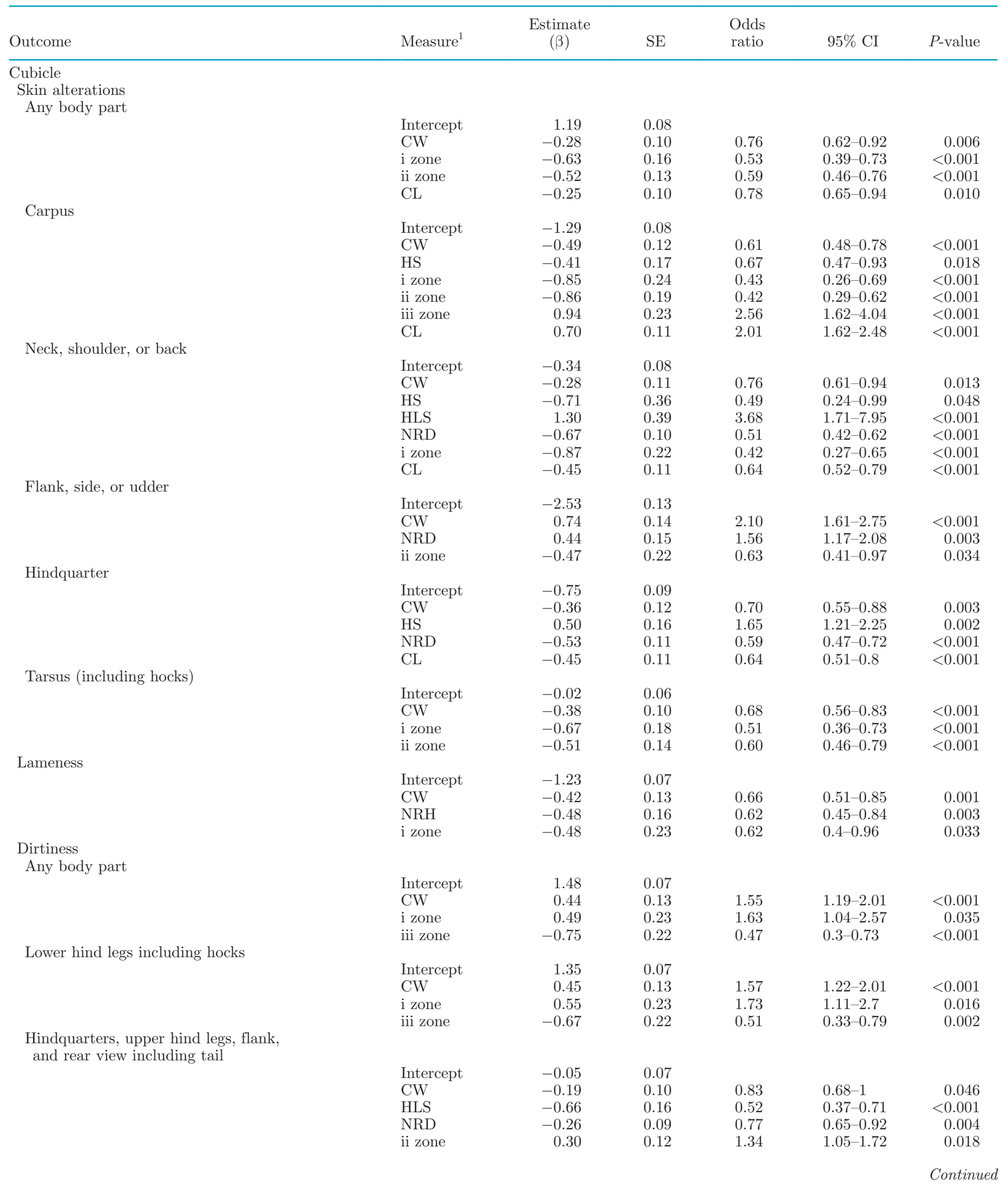


Table 4 (Continued). Coefficient of multivariable logistic regression models between International Commission of Agricultural and Biosystems Engineering (CIGR) recommendations for cubicles, self-locking barriers, and cubicles + self-locking barriers and prevalence of skin alterations, lameness, and dirtiness in cows

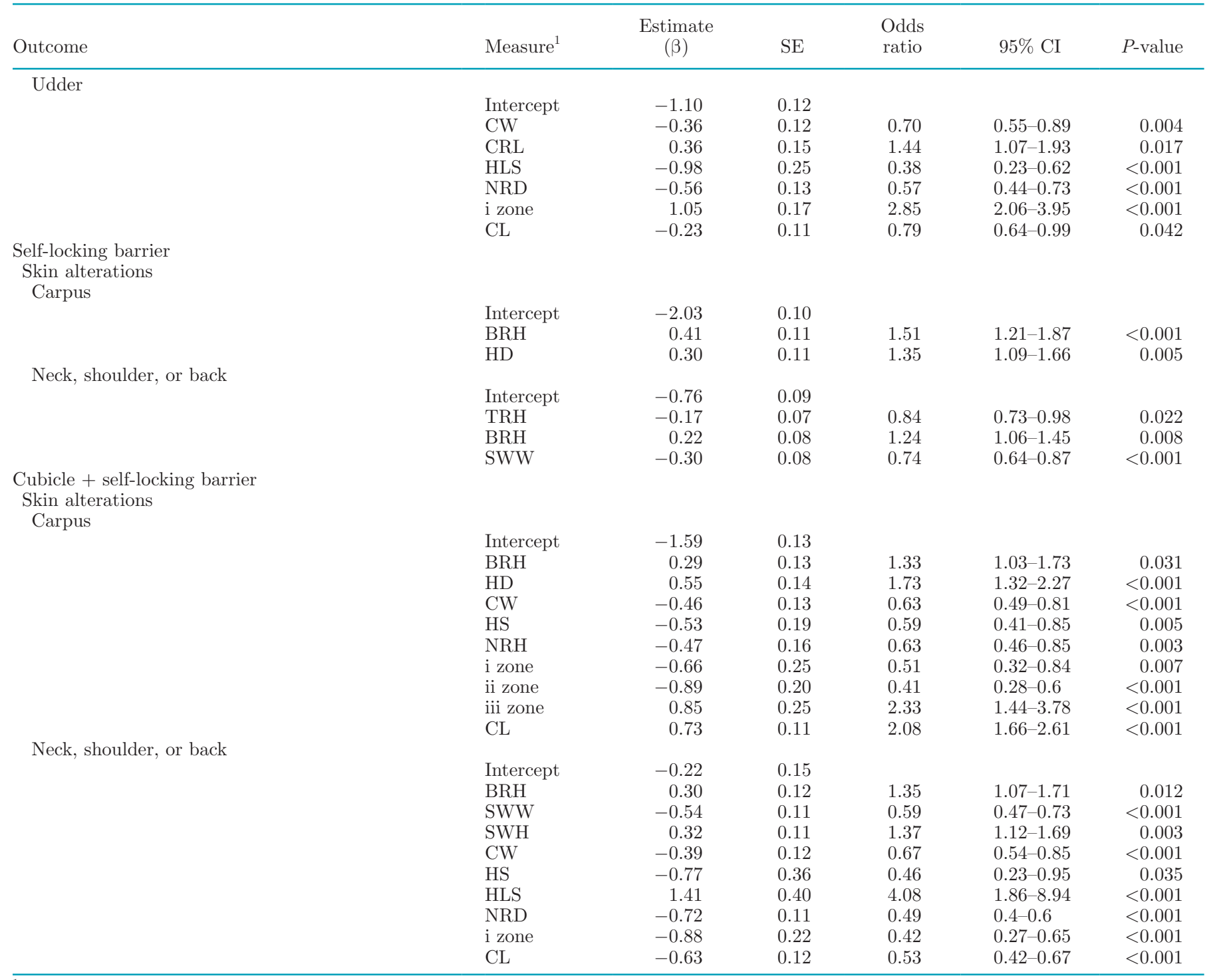

${ }^{1}$ Definitions of all measures can be found in Table 2 .

mendations for $\mathrm{CW}(\mathrm{OR}=0.82)$, $\mathrm{HLS}(\mathrm{OR}=0.52)$, and NRD $(\mathrm{OR}=0.77)$ but increased when cubicles met recommendations for ii zone $(\mathrm{OR}=1.34)$. The risks for dirty udder decreased when cubicles met recommendations for $\mathrm{CW}(\mathrm{OR}=0.69), \mathrm{CL}(\mathrm{OR}=0.79)$, HLS $(\mathrm{OR}$ $=0.37)$, and $\mathrm{NRD}(\mathrm{OR}=0.57)$ but increased when cubicles met recommendations for $\mathrm{CRL}(\mathrm{OR}=1.43)$ and i zone $(\mathrm{OR}=2.85)$.

According to the final model for lameness, the risks decreased when cubicles met recommendations for $\mathrm{CW}$ $(\mathrm{OR}=0.66), \mathrm{NRH}(\mathrm{OR}=0.61)$, and i zone $(\mathrm{OR}=$ $0.62)$.

\section{Association Between CIGR Recommendations for Self-Locking Barriers and Skin Alterations}

According to the final models for skin alterations (data set 2; Tables 4 and 5), the risks for carpus injury increased when self-locking barriers met recommendations for $\mathrm{BRH}(\mathrm{OR}=1.50)$ and $\mathrm{HD}(\mathrm{OR}=1.35)$. The risks for neck, shoulder, or back injury decreased when self-locking barriers met recommendations for TRH $(\mathrm{OR}=0.84)$ and SWW $(\mathrm{OR}=0.74)$ but increased when self-locking barriers met recommendations for $\mathrm{BRH}(\mathrm{OR}=1.24)$. 


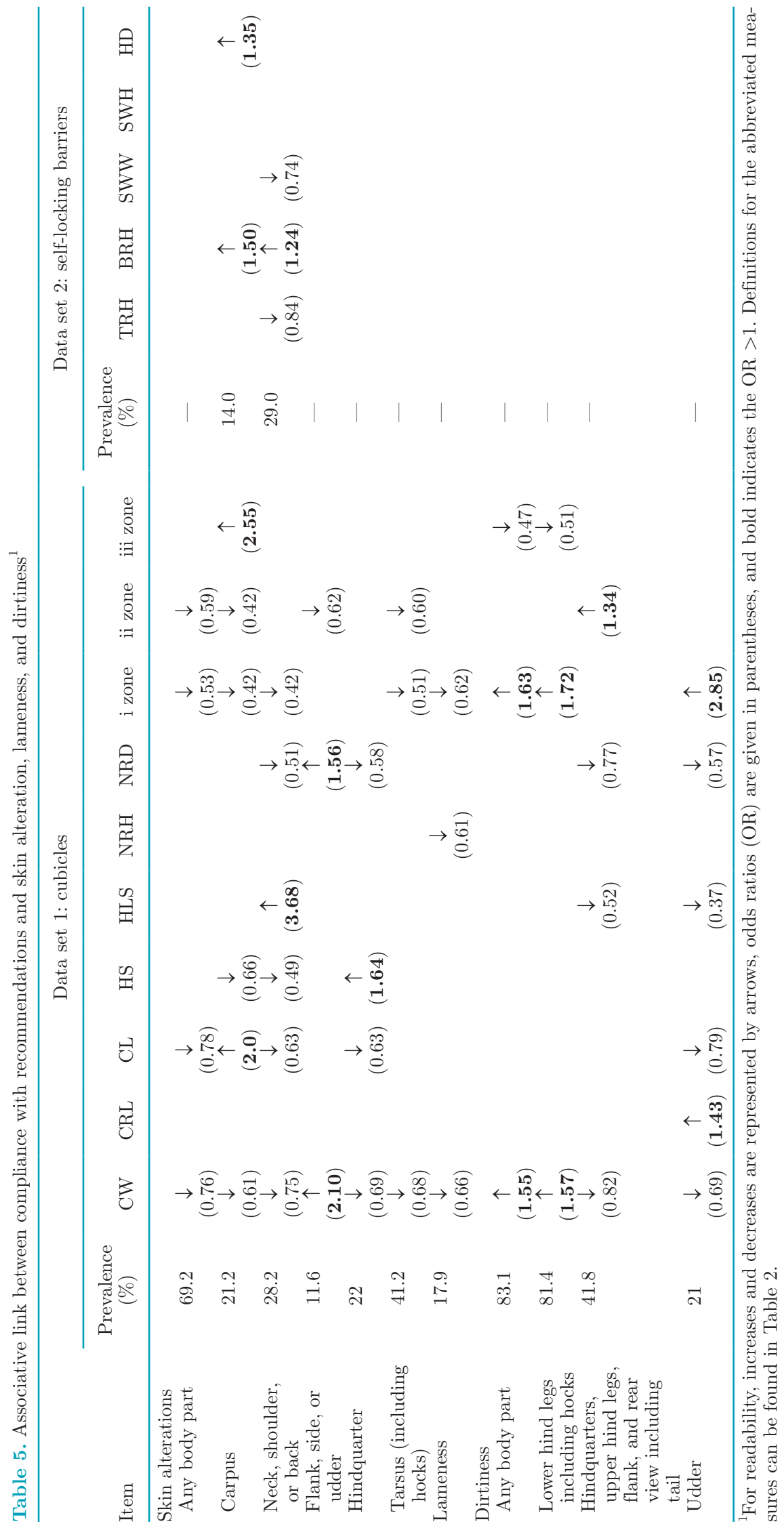




\section{Association Between CIGR Recommendations for Cubicles and Self-Locking Barriers, and Skin Alterations}

According to the final models for skin alterations on neck, shoulder, or back and carpus (data set 3; Table 4), the risk for carpus injury decreased when cubicles met recommendations for $\mathrm{CW}(\mathrm{OR}=0.63)$, $\mathrm{HS}(\mathrm{OR}$ $=0.59), \mathrm{NRH}(\mathrm{OR}=0.63)$, i zone $(\mathrm{OR}=0.51)$, and ii zone $(\mathrm{OR}=0.41)$. These risks increased when selflocking barriers met recommendations for $\mathrm{BRH}$ (OR $=1.33)$ and $\mathrm{HD}(\mathrm{OR}=1.73)$ and when cubicles met recommendations for $\mathrm{CL}(\mathrm{OR}=2.08)$ and iii zone $(\mathrm{OR}$ $=2.33)$.

The risk for neck, shoulder, or back injury decreased when self-locking barriers met recommendations for SWW $(\mathrm{OR}=0.58)$ and when cubicles met recommendations for $\mathrm{CW}(\mathrm{OR}=0.67)$, $\mathrm{HS}(\mathrm{OR}=0.46)$, $\mathrm{NRD}$ $(\mathrm{OR}=0.49)$, i zone $(\mathrm{OR}=0.42)$, and $\mathrm{CL}(\mathrm{OR}=0.53)$. These risks increased when self-locking barriers met recommendations for $\mathrm{BRH}(\mathrm{OR}=1.35)$ and $\mathrm{SWH}(\mathrm{OR}$ $=1.37)$ and when cubicles met recommendations for HLS $(\mathrm{OR}=4.08)$.

\section{DISCUSSION}

Almost $70 \%$ of the observed cows had at least one skin alteration. This result is consistent with observed prevalence rates already reported by previous studies in freestall housing in North America and Europe (Weary and Taszkun, 2000; Huxley et al., 2004; Kielland et al., 2009, 2010). Among the cows observed, $17.9 \%$ were lame, which is slightly lower than previously reported in cubicle systems (e.g., 29.3\% in Espejo et al., 2006; $31 \%$ in Dippel et al., 2009; 21\% in Solano et al., 2015). The prevalence of dirtiness differed between body parts. Compared with Main et al. (2003) and Whay et al. (2003), here we found cows were less dirty on their lower hind legs (100 and $100 \%$ vs. $81 \%$ here), equally dirty on their udder (20 and $22 \%$ vs. $21 \%$ here), but dirtier on the hindquarters, upper hind legs, flanks, or rear view (11 and $17 \%$ vs. $42 \%$ here).

On the whole, the majority of cubicles and self-locking barriers on the farms surveyed here did not meet the CIGR (2014) recommendations. In 50\% of cases, only 2 of the 10 cubicle dimensions (CRL and NRD) and 3 of the 5 self-locking barrier dimensions (BRH, SWW, and TRH) were met. This lack of compliance with the recommendations is consistent with findings from earlier studies on tiestalls in Canada (Zurbrigg et al., 2005; Bouffard et al., 2017) and on freestalls in Norway (Sogstad et al., 2005).

The recommendations for $\mathrm{CW}$ are calculated from cow body dimensions. We found that compliance with the recommendations was associated with lower risks for skin alterations (on neck, tarsus, carpus, and hindquarters), lameness, and dirty hindquarters and udders. Studies have found increased risk of lameness in cubicles that were too narrow (Sogstad et al., 2005) and too wide (Dippel et al., 2009) but no association between skin injuries on the legs and CW (Kielland et al., 2009). However, these studies did not consider CW according to cow body dimensions. The only 2 studies taking cow body size into account found contradictory results. Veissier et al. (2004) found that CW was not associated with skin injury, lameness, or dirtiness. On the contrary, Westin et al. (2016) found that CW relative to cow size was the most important factor associated with lameness; the risk increased when the stall was too narrow for the cow. The CIGR recommendation for CW thus seems to help reduce skin alterations and dirtiness on most cow body parts and lameness.

According to the CIGR (1994, 2014), cubicle length (CL, CRL) must be large enough to enable the cow to rest comfortably on the floor and to stand with all feet in the cubicle. Cubicles that are too short can increase the frequency of standing with only the forefeet inside the cubicle, leading to hoof problems and increased prevalence of lameness (Sogstad et al., 2005; Dippel et al., 2009). It can also compress the hocks when the cow is lying down and increase the prevalence of skin alterations on hocks (Weary and Taszkun, 2000). However, again, these earlier studies did not take cow body dimensions into account. Here, we found that compliance with the CIGR recommendations on CRL taking cow size into account was associated with increased risks for dirty udder but decreased risks for lameness. We also observed that compliance with the CIGR recommendations on CL was associated with lower risks for skin alterations on neck, shoulder, or back and on hindquarters and with lower risks for dirty udders. It was, however, associated with increased risks for skin alterations on carpus. Our findings therefore confirm that the CIGR recommendations for CL can help reduce skin alterations on most body parts but that CIGR recommendations for CRL also appear to increase dirtiness on udder. We therefore need to balance the issues regarding injuries versus cleanliness. Changes in cubicles design to meet recommendations to ensure less skin alterations and lameness may require, at the same time, changes in management practices (e.g., more cleaning) or resource choices (e.g., alternative bedding options) to ensure better cleanliness.

Again, according to the CIGR, the space in front of cubicles (HS and HLS) needs to be long enough to allow the cow to rise up and lie down without colliding with equipment. Indeed, here we found that compliance with the recommendation on HS was associated with lower 
risks for skin injury on the carpus and on the neck, shoulder, or back but increased risks for skin injury on hindquarters, whereas compliance with the recommendation on HLS was associated with increased risk for skin injury on the neck, shoulder, or back. According to the CIGR, HS should be at least 0.48 of cow height and HLS should be at least 0.65 of cow height. Our findings confirm the appropriateness of the CIGR calculation to define HS but indicate that the HLS should be larger than proposed by CIGR to prevent injuries on the neck, shoulder, or back. Indeed, cows need space ahead to perform their lying down and rising up movement: too narrow of space ahead may lead to collisions and skin injuries, especially on the neck, shoulder, or back. This hypothesis needs, however, to be confirmed by further behavioral observations.

The neck rail encourages cows to move backward when rising up and prevents them from standing too far forward in the cubicle (CIGR, 2014). To function properly, it should be located below the cow's withers (Veissier et al., 2004). Some studies have observed an association between NRH and skin alterations (e.g., injuries were more common when the neck rail was high, Veissier et al., 2004), but most studies have found no association with skin alteration or lameness (Veissier et al., 2004; Sogstad et al., 2005; Kielland et al., 2009; Zaffino Heyerhoff et al., 2014; Westin et al., 2016). Here, $\mathrm{NRH}$ met the CIGR recommendation in $22 \%$ of cases. Compliance with the recommendation was associated with lower risks for lameness. Our results thus confirm that the CIGR-recommended NRH is appropriate.

Previous studies have reported that a long NRD from the curb leads to less hock injury (Zaffino Heyerhoff et al., 2014) but also to an increased prevalence of dirty udder (Fregonesi et al., 2009). Here, the CIGR recommendation for NRD from the curb was met in $60 \%$ of cases. Compliance with the recommendation was associated with lower risks for skin injury on the neck, shoulder, or back and on the hindquarters and with dirty udder and dirty hindquarters, upper hind legs, flanks, and rear view. However, it leads to increased risks for skin alterations on the flank, side, or udder. The balance thus tips in favor of the CIGR recommendation for NRD from the curb. Interestingly, when cubicles met both NRD and NRH recommendations (13.1\% of the cases in our study, Supplemental Table S3; https://doi.org/10.3168/jds.2018-16154), the prevalences of lameness, skin alterations, and dirtiness on most body parts were all significantly lower. It seems therefore that the overall adjustment of the neck rail (i.e., combining height and distance) proposed by the CIGR recommendations is a highly important way to improve cow welfare and cleanliness.
The CIGR defines several zones of cubicle partitions: the head zone, the zone for controlling lying position, and the zone for pelvis freedom to prevent injuries to hips and ribs. We did not find data in the literature relating these 3 zones to disorders in cows. In our study, the CIGR recommendations on these cubicle zones were rarely met. A nonobstructed head zone was associated with lower risks for skin alteration on the carpus, neck, and hindquarters; lower risks for lameness; but increased risks for dirty lower hind legs and dirty udder. An appropriate zone for controlling the lying position of the cow was associated with lower risks for skin alterations on the carpus, udder, and hindquarters. However, it was also associated with increased risks for dirty hindquarters. Finally, a nonobstructed zone for the pelvis was associated with increased risks for skin alteration on the carpus but with decreased risks for dirty lower hind legs. These results suggest that the CIGR recommendations on the configuration of partitions between cubicles should be updated and should take into account cleaning frequency or choice of bed type to ensure both cleanliness and skin integrity. Further close observation on the positioning and movements of cows in cubicles is needed to define ergonomic cubicle partitions.

Self-locking feeding barriers can help prevent competition and are useful for animal observation and treatment (CIGR, 2014). However, inappropriate physical restrictions may cause skin alterations (Kielland et al., 2010). Only 2 studies so far have assessed the link between feed barrier dimensions and the risk for skin alterations on the neck. Kielland et al. (2009) did not find an association between self-locking barrier design and neck injuries, possibly because they did not take into account the cow dimension in their analysis. Interestingly, they also observed post-and-rail barriers and found that for a 98- to 109-cm-high top rail, risk of neck lesions increased exponentially with increasing shoulder height. The association among feeding barrier design, cow height, and neck injuries was confirmed by Zaffino Heyerhoff et al. (2014), who showed that risk for neck injuries increased with decreasing top rail height. Surprisingly, compliance with the recommendations for BRH was associated with increased risks for skin alterations on the carpus and neck, shoulder, or back, and compliance with the recommendations for height difference between feeding floor and walking alley (HD) was associated with increased risks for skin alterations on the carpus. Only the recommendations for the TRH and SWW were associated with lower risks for skin injury on the carpus. Again, our findings call for further research involving close observation of cows when feeding to refine the CIGR recommendations for self- 
locking barriers (Supplemental Table S4; https://doi .org/10.3168/jds.2018-16154).

The models combining information from cubicles and self-locking barriers demonstrated that the risks for skin alterations on neck, shoulders, or back increased when cubicles and self-locking barriers met the recommendation respectively for $\mathrm{HLS}, \mathrm{SWH}$, and $\mathrm{BRH}$ but decreased when self-locking barriers met recommendations for SWW and when cubicles met recommendations for CW, CL, HS, NRD, and i zone. These results are consistent with those of previous models and are helpful to highlight the most important factors to prevent skin alterations. Again, our findings call for further research to refine the CIGR recommendations for more ergonomic cubicle partitions and self-locking barriers dimensions.

Our study focused on equipment dimensions, but other factors such as type, comfort, or presence of hurtful zones on cubicles and self-locking barriers may play key roles in the emergence of the welfare outcomes addressed here (e.g., Ruud et al., 2010b; Potterton et al., 2011). For instance, a more comfortable lying surface may compensate for suboptimal stall dimensions, and a hard floor may still cause skin alterations even when the CIGR recommendations are met. Similarly, a frequent distribution of feed may compensate for suboptimal self-locking barrier dimensions, and a protruding nut may still cause skin alterations even when the CIGR recommendations are met. However, the findings presented here should be considered cautiously because they present associative (but not causal) links between dimensions and cow welfare. Further work integrating cubicle and self-locking barrier design and other management information into models of risk assessment for skin injury, lameness, and dirtiness could be used to address these issues on dairy farms.

\section{CONCLUSIONS}

Most dairy cows that we surveyed had welfare problems, mainly skin alterations and dirtiness. This is partly explained by the fact that the CIGR recommendations are rarely met. Indeed, following the recommendations for cubicle dimensions and the positioning of the neck rail and $\mathrm{CW}$ were associated with lower risk for cow welfare. Nevertheless, the recommendations for the design of cubicle partitions and self-locking barriers still leave animal welfare at risk. Further work integrating cubicle and self-locking barrier design and other information into models of risk assessment for skin injury, lameness, and dirtiness could be used to address these issues on dairy farms.

\section{ACKNOWLEDGMENTS}

This work received financial support from Danone Research (Paris, France), pole Enseignement Sciences Technologiques et d'Innovation dans les domaines du Vivant et de l'Environnement (ESTIVE), and the French government [Initiative D'EXcellence-Initiative Science-Innovation-Territoires-Économie (IDEXISITE) initiative 16-IDEX-0001, Clermont-Auvergne Projet (CAP) 20-25, Clermont-Ferrand, France]. We thank the "Groupements de Défense Sanitaire" for providing lists of eligible farms and all the farmers who willingly cooperated in this survey. We are also particularly grateful to Eric Delval (INRA, Clermont-Ferrand, France), Christophe Mallet (INRA), Maud Coignard of Nantes-Atlantic National College of Veterinary Medicine, Food Science and Engineering (ONIRIS, Nantes, France), and Remi Debauchez of the Institut supérieur d'agriculture Rhône-Alpes (ISARA, Lyon, France) for their help with data collection; Jean-Yves Audiart (ONIRIS), Didier Billon (ONIRIS), and Eric Delval (INRA) for their help with data entry; and Jos Noordhuizen, Raphaël Guatteo (ONIRIS), Nathalie Bareille (ONIRIS), and Claire Agabriel (VetAgro Sup, Clermont-Ferrand, France) for their valuable advice on survey design. The authors thank Metaform Langues for their editorial support and English reviewing.

\section{REFERENCES}

Akaike, H. 1973. Information theory and an extension of the maximum likelihood principle. Pages 267-281 2nd Int. Symp. Info. Theory. Akademiai Kiado, Budapest, Hungary.

Bouffard, V., A. M. de Passillé, J. Rushen, E. Vasseur, C. G. R. Nash, D. B. Haley, and D. Pellerin. 2017. Effect of following recommendations for tiestall configuration on neck and leg lesions, lameness, cleanliness, and lying time in dairy cows. J. Dairy Sci. 100:29352943. https://doi.org/10.3168/jds.2016-11842.

Burnham, K. P., D. R. Anderson, and K. P. Huyvaert. 2011. AIC model selection and multimodel inference in behavioral ecology: Some backgrounds, observations, and comparisons. Behav. Ecol. Sociobiol. 65:23-35. https://doi.org/10.1007/s00265-010-1029-6.

CIGR (International Commission of Agricultural and Biosystems Engineering). 1994. The Design of Dairy Cows Housing. Report of the CIGR Working Group No. 14. ADAS Bridgets Dairy Res. Cent., Farm Build. Res. Team, Reading, UK.

CIGR (International Commission of Agricultural and Biosystems Engineering). 2014. The Design of Dairy Cow and Replacer Heifer Housing. Report of the CIGR Section II Working Group No. 14, Cattle Housing. CIGR, Gainesville, FL.

Cook, N. B. 2003. Prevalence of lameness among dairy cattle in Wisconsin as a function of housing type and stall surface. J. Am. Vet. Med. Assoc. 223:1324-1328.

Dairy Farmers of Canada and National Farm Animal Care Council. 2009. Code of Practice for the Care and Handling of Farm Animals-Dairy Cattle. Dairy Farmers of Canada. Accessed Aug. 5, 2019. https://www.dairyresearch.ca/animal-comfort-tool.php.

de Boyer des Roches, A., I. Veissier, X. Boivin, E. Gilot-Fromont, and L. Mounier. 2016. A prospective exploration of farm, farmer, and animal characteristics in human-animal relationships: An epide- 
miological survey. J. Dairy Sci. 99:5573-5585. https://doi.org/10 .3168/jds.2015-10633.

de Boyer des Roches, A., I. Veissier, M. Coignard, N. Bareille, R. Guatteo, J. Capdeville, E. Gilot-Fromont, and L. Mounier. 2014. The major welfare problems of dairy cows in French commercial farms: An epidemiological approach. Anim. Welf. 23:467-478. https://doi.org/10.7120/09627286.23.4.467.

de Boyer des Roches, A., I. Veissier, B. Renaud, J. Capdeville, E. Gilot-Fromont, and L. Mounier. 2013. Taking cows body dimension when designing housing system: A way to improve dairy cows well being. Page 180 in Behaviour 2013, 33rd Int. Ethological Conf., Newcastle, UK.

Dippel, S., M. Dolezal, C. Brenninkmeyer, J. N. Brinkmann, S. March, U. Knierim, and C. Winckler. 2009. Risk factors for lameness in cubicle housed Austrian Simmental dairy cows. Prev. Vet. Med. 90:102-112.

Espejo, L. A., M. I. Endres, and J. A. Salfer. 2006. Prevalence of lameness in high-producing Holstein cows housed in freestall barns in Minnesota. J. Dairy Sci. 89:3052-3058. https://doi.org/10.3168/ jds.S0022-0302(06)72579-6.

European Food Safety Authority. 2009. Scientific report on the effect of farming systems on dairy cow welfare and disease. EFSA J. 7:1143r. https://doi.org/10.2903/j.efsa.2009.1143r.

European Food Safety Authority. 2012. Scientific opinion on the use of animal-based measures to assess welfare of dairy cows by the EFSA Panel on Animal Health and Welfare (AHAW). EFSA J. 10:2554. https://doi.org/10.2903/j.efsa.2012.2554.

Fregonesi, J. A., and J. D. Leaver. 2002. Influence of space allowance and milk yield level on behaviour, performance and health of dairy cows housed in strawyard and cubicle systems. Livest. Prod. Sci. 78:245-257. https://doi.org/10.1016/S0301-6226(02)00097-0.

Fregonesi, J. A., M. A. G. von Keyserlingk, C. B. Tucker, D. M. Veira, and D. M. Weary. 2009. Neck-rail position in the free stall affects standing behavior and udder and stall cleanliness. J. Dairy Sci. 92:1979-1985. https://doi.org/10.3168/jds.2008-1604.

Huxley, J. N., J. Burke, S. Roderick, D. C. J. Main, and H. R. Whay. 2004. Animal welfare assessment benchmarking as a tool for health planning in organic dairy herds. Vet. Rec. 155:237-239. https:// doi.org/10.1136/vr.155.8.237.

Kielland, C., K. E. Bøe, A. J. Zanella, and O. Østerås. 2010. Risk factors for skin lesions on the necks of Norwegian dairy cows. J. Dairy Sci. 93:3979-3989. https://doi.org/10.3168/jds.2009-2909.

Kielland, C., L. E. Ruud, A. J. Zanella, and O. Østerås. 2009. Prevalence and risk factors for skin lesions on legs of dairy cattle housed in freestalls in Norway. J. Dairy Sci. 92:5487-5496. https://doi .org/10.3168/jds.2009-2293.

Main, D. C. J., H. R. Whay, L. E. Green, and A. J. F. Webster. 2003. Effect of the RSPCA Freedom food scheme on the welfare of dairy cattle. Vet. Rec. 153:227-231. https://doi.org/10.1136/vr .153.8.227.

Potterton, S. L., M. J. Green, J. Harris, K. M. Millar, H. R. Whay, and J. N. Huxley. 2011. Risk factors associated with hair loss, ulceration, and swelling at the hock in freestall-housed UK dairy herds. J. Dairy Sci. 94:2952-2963. https://doi.org/10.3168/jds .2010-4084

Prunier, A., L. Mounier, P. Le Neindre, C. Leterrier, P. Mormede, V. Paulmier, P. Prunet, C. Terlouw, and R. Guatteo. 2013. Iden- tifying and monitoring pain in farm animals: A review. Animal 7:998-1010. https://doi.org/10.1017/S1751731112002406.

R Core Team. 2018. R: A Language and Environment for Statistical Computing. R Found. Stat. Comput., Vienna, Austria.

Reneau, J. K., A. J. Seykora, B. J. Heins, M. I. Endres, R. J. Farnsworth, and R. F. Bey. 2005. Association between hygiene scores and somatic cell scores in dairy cattle. J. Am. Vet. Med. Assoc. 227:1297-1301. https://doi.org/10.2460/javma.2005.227.1297.

Ruud, L. E., K. E. Bøe, and O. Østerås. 2010a. Risk factors for dirty dairy cows in Norwegian freestall systems. J. Dairy Sci. 93:52165224. https://doi.org/10.3168/jds.2010-3321.

Ruud, L. E., K. E. Bøe, and O. Østerås. 2010b. Associations of soft flooring materials in free stalls with milk yield, clinical mastitis, teat lesions, and removal of dairy cows. J. Dairy Sci. 93:1578-1586. https://doi.org/10.3168/jds.2009-2752.

Schreiner, D. A., and P. L. Ruegg. 2003. Relationship between udder and leg hygiene scores and subclinical mastitis. J. Dairy Sci. 86:3460-3465. https://doi.org/10.3168/jds.S0022-0302(03)73950 -2 .

Sogstad, Å., T. Fjeldaas, and O. Østerås. 2005. Lameness and claw lesions of the Norwegian Red dairy cattle housed in free stalls in relation to environment, parity and stage of lactation. Acta Vet. Scand. 46:203-217. https://doi.org/10.1186/1751-0147-46-203.

Solano, L., H. W. Barkema, E. A. Pajor, S. Mason, S. J. LeBlanc, J. C. Zaffino Heyerhoff, C. G. R. Nash, D. B. Haley, E. Vasseur, D. Pellerin, J. Rushen, A. M. de Passillé, and K. Orsel. 2015. Prevalence of lameness and associated risk factors in Canadian HolsteinFriesian cows housed in freestall barns. J. Dairy Sci. 98:6978-6991. https://doi.org/10.3168/jds.2015-9652.

Veissier, I., J. Capdeville, and E. Delval. 2004. Cubicle housing systems for cattle: Comfort of dairy cows depends on cubicle adjustment. J. Anim. Sci. 82:3321-3337.

Weary, D. M., and I. Taszkun. 2000. Hock lesions and free-stall design. J. Dairy Sci. 83:697-702. https://doi.org/10.3168/jds.S0022 $-0302(00) 74931-9$

Welfare Quality. 2009. Welfare Quality Assessment Protocol for Cattle. Welfare Quality Consort., Lelystad, the Netherlands.

Westin, R., A. Vaughan, A. M. de Passillé, T. J. DeVries, E. A. Pajor, D. Pellerin, J. M. Siegford, A. Witaifi, E. Vasseur, and J. Rushen. 2016. Cow- and farm-level risk factors for lameness on dairy farms with automated milking systems. J. Dairy Sci. 99:3732-3743. https://doi.org/10.3168/jds.2015-10414.

Whay, H. R., D. C. J. Main, L. E. Green, and A. J. F. Webster. 2003. Assessment of the welfare of dairy cattle using animal-based measurements: Direct observations and investigation of farm records. Vet. Rec. 153:197-202. https://doi.org/10.1136/vr.153.7.197.

Zaffino Heyerhoff, J. C., S. J. LeBlanc, T. J. DeVries, C. G. R. Nash, J. Gibbons, K. Orsel, H. W. Barkema, L. Solano, J. Rushen, A. M. de Passillé, and D. B. Haley. 2014. Prevalence of and factors associated with hock, knee, and neck injuries on dairy cows in freestall housing in Canada. J. Dairy Sci. 97:173-184. https://doi .org/10.3168/jds.2012-6367.

Zurbrigg, K., D. Kelton, N. Anderson, and S. Millman. 2005. Stall dimensions and the prevalence of lameness, injury, and cleanliness on 317 tie-stall dairy farms in Ontario. Can. Vet. J. 46:902-909. 